\title{
Voluntary wheel running in mice increases the rate of neurogenesis without affecting anxiety-related behaviour in single tests
}

Lillian Garrett ${ }^{1,3}$, D Chichung Lie ${ }^{1}$, Martin Hrabé de Angelis ${ }^{2,3,5}$, Wolfgang Wurst ${ }^{1,4,6,7^{*}}$ and Sabine M Hölter ${ }^{1,3,4^{*}}$

\begin{abstract}
Background: The role played by adult neurogenesis in anxiety is not clear. A recent study revealed a surprising positive correlation between increased anxiety and elevated neurogenesis following chronic voluntary wheel running and multiple behavioural testing in mice, suggesting that adult hippocampal neurogenesis is involved in the genesis of anxiety. To exclude the possible confounding effect of multiple testing that may have occurred in the aforementioned study, we assessed (1) the effects of mouse voluntary wheel running (14 vs. 28 days) on anxiety in just one behavioural test; the open field, and (2), using different markers, proliferation, differentiation, survival and maturation of newly born neurons in the dentate gyrus immediately afterwards. Effects of wheel running on anxiety-related behaviour were confirmed in a separate batch of animals tested in another test of anxiety, the light/dark box test.

Results: Running altered measures of locomotion and exploration, but not anxiety-related behaviour in either test. 14 days running significantly increased proliferation, and differentiation and survival were increased after both running durations. 28 day running mice also exhibited an increased rate of maturation. Furthermore, there was a significant positive correlation between the amount of proliferation, but not maturation, and anxiety measures in the open field of the 28 day running mice.
\end{abstract}

Conclusions: Overall, this evidence suggests that without repeated testing, newly born mature neurons may not be involved in the genesis of anxiety per se.

\section{Background}

Adult mammalian hippocampal neurogenesis is the birth of new neurons from neural precursor cells in the subgranular zone of the dentate gyrus [1-3]. This process can be subdivided into a series of distinct phases that begins with proliferation of Type II neural precursor cells, followed by neuronal lineage specification, migration, maturation and synaptic integration into existing hippocampal neurocircuitry [4]. The precise functional role of these newly generated granule cells is not known [5]. While much of the available research has focused on their role in learning and memory $[6,7,8]$, there is also

\footnotetext{
*Correspondence: wurst@helmholtz-muenchen.de; hoelter@helmholtzmuenchen.de

'Institute of Developmental Genetics, Helmholtz Zentrum München, German Research Center for Environmental Health, Neuherberg/Munich, Germany ${ }^{4}$ Technische Universität München, Lehrstuhl für Entwicklungsgenetik, Freising-Weihenstephan, Germany

Full list of author information is available at the end of the article
}

evidence linking neurogenesis to emotion-related behaviours such as anxiety [6,9-11]. The widely held view is that decreased neurogenesis is associated with increased anxiety [12-14], with some evidence to the contrary $[6,8,15]$.

A frequently used means to experimentally increase neurogenesis in mice is voluntary wheel running/exercise $[3,16]$. Few studies have directly tested the relationship between exercise-induced neurogenesis and anxiety-related behaviour. A recent investigation was one of the first to explore this association [17]. The outcome revealed that three to four weeks running caused a surprising increase in anxiety-related behaviour in mice that positively correlated with elevated measures of neurogenesis. The conclusion that increased neurogenesis plays a role in the genesis of anxiety is in opposition to the widely held view. Nevertheless, this study involved an extensive behavioural test battery, the stressful nature of which, as well as the

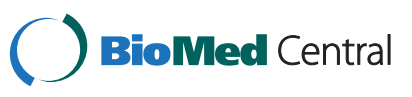


prolonged period of time before animals were sacrificed (in total 45 days), could have affected neurogenesis. Furthermore, the experience of multiple test exposures and handling involves learning and might have affected behavioural measures [18]. In the current study, we addressed these confounding issues and directly asked the question whether exercise-induced neurogenesis increases anxiety responding without any prior experience. To this end we looked at the effects of 14 and 28 days voluntary wheel running in mice on just one set of behaviours; those in the open field test. The animals were sacrificed immediately after to avoid the confounding effect of repeated testing and to assess the different phases of neurogenesis (proliferation, survival, differentiation and maturation) at the time point of testing. To confirm the effects of wheel running on anxiety-related behaviour this experiment was repeated in a separate batch of animals, but instead of the open field the animals were tested in another test for anxiety, the light/dark box test.

\section{Methods}

Animals

Male C57BL/6 J mice (cohort 1: $\mathrm{n}=39$, cohort 2: $\mathrm{n}=20$ ) were obtained at 7 weeks of age from the animal breeding unit of the Helmholtz Zentrum München. Upon their arrival, animals were singly housed in individually ventilated cages in a temperature $\left(22-24^{\circ} \mathrm{C}\right)$ and humidity $(50-60 \%)$ controlled environment on a 12 / $12 \mathrm{~h}$ light/dark cycle (lights on at $7 \mathrm{am}$ ). Water and food were available ad libitum. All experiments were carried out in accordance with the European Communities Council Directive of 24 November 1986 (86/609/EEC) and approved by the responsible animal welfare authority (Regierung von Oberbayern).

\section{Voluntary wheel running}

The experimental timeline is illustrated in Figure 1A. After a 1 week acclimatisation period, mice randomly assigned to the 14- and 28-day running groups ( $\mathrm{n}=16$ and 14 respectively) were provided with an angled running wheel (diameter $15.50 \mathrm{~cm}$ ) complete with a wire-less controlled activity counter (Wheel Manager software, Med Associates Inc., VT, USA). These time-points were chosen as changes in anxiety-related behaviour had previously been shown after this amount of exercise $[19,20]$ and also newly born neurons have functionally matured by the 28 day time-point [21]. Running wheels were removed $24 \mathrm{~h}$ prior to behavioural testing. Sedentary control animals $(n=14-15$ per group) were singly housed for the duration of the experiment without a running wheel. As an additional measure of anxiety-related behaviour, a separate batch of C57BL/6 J mice ( $n=10$ sedentary controls, $n=10$ wheel runners) were subjected to the same experimental sequence but exposed to the light/dark box test on completion of 28 days running.
To exclude the possible confounding effect of wheel removal the day before behavioural testing, which may be stressful for the animal because it is a change in their environment, an additional blocked wheel control group $(n=10)$ was included.

\section{BrdU injection}

5'-bromo-2'-deoxyuridine (BrdU) (Sigma, Germany) was dissolved in a $0.9 \%(\mathrm{w} / \mathrm{v}) \mathrm{NaCl}$ solution. After one day running, experimental animals and controls were injected with $50 \mathrm{mg} / \mathrm{kg}$ BrdU intra-peritoneally once a day for 3 days.

\section{Open field analysis}

On completion of the respective running periods, all animals were tested the next day during the light phase using the open field test, which consisted of a transparent and infra-red light permeable acrylic test arena with a smooth floor (internal measurements: $45.5 \times 45.5$. x $39.5 \mathrm{~cm}$ ). Illumination levels were set at approx. 150 lux in the corners and 200 lux in the middle of the test arena. Data were recorded and analysed using the ActiMot system (TSE, Bad Homburg, Germany).

\section{Light/dark box analysis}

The test box was made of PVC and divided into two compartments, connected by a small tunnel (4 x 6 x $9 \mathrm{~cm}$ high). The lit compartment ( $29 \times 19 \times 24 \mathrm{~cm}$ high) was made of transparent PVC and was illuminated by cold light with an intensity of 650 lux in the middle; the dark compartment (14 x $19 \times 24 \mathrm{~cm}$ high) was made of black PVC and not directly illuminated (approx. 20 lux in the centre). The mouse was placed in the centre of the black compartment and allowed to freely explore the apparatus for $5 \mathrm{~min}$. Data were recorded and analysed using the ActiMot system (TSE, Bad Homburg, Germany).

\section{Tissue preparation}

The day after open field and light/dark box analysis, animals were deeply anaesthetised using $\mathrm{CO}_{2}$ and perfused transcardially with $4 \%$ paraformaldehyde (PFA) in $0.1 \mathrm{M}$ phosphate buffer. Brains were dissected from the skulls, post-fixed overnight in $4 \% \mathrm{PFA}$ at $4^{\circ} \mathrm{C}$ and then transferred to a $30 \%(\mathrm{w} / \mathrm{v})$ sucrose solution until saturated. Brains were then cut on a dry ice-cooled block with a sliding microtome (Leica, Bensheim) into $40 \mu \mathrm{m}$-thick coronal free-floating sections and stored at $-20^{\circ} \mathrm{C}$ in a cryoprotectant solution containing $25 \%$ ethylene glycol and $25 \%$ glycerine in phosphate buffer. A one-in-six series of sections was taken for analysis from the brains of a subset of animals from each group. 


\section{A}

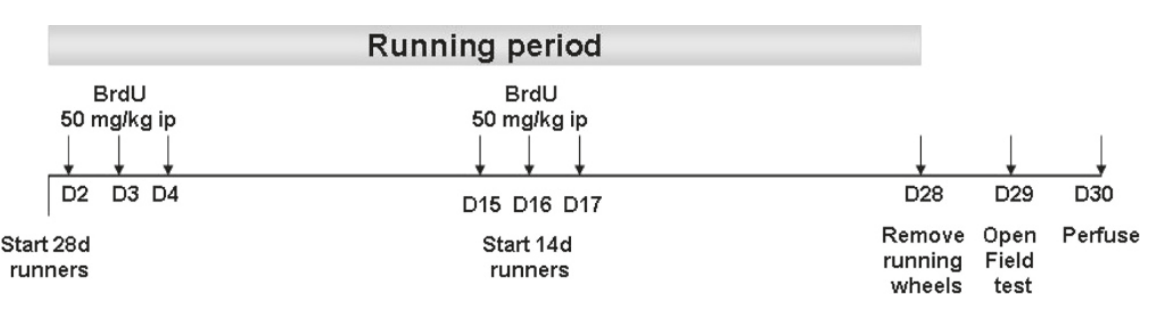

B

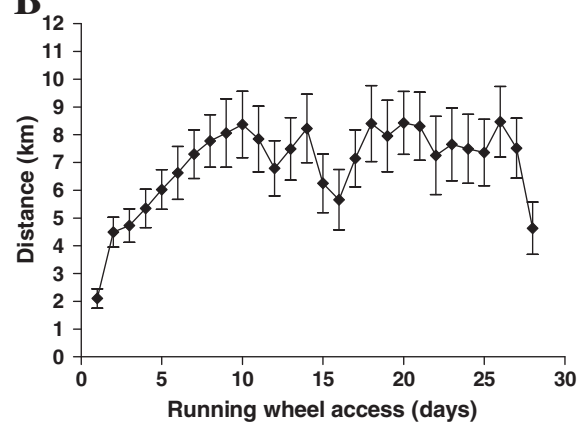

C

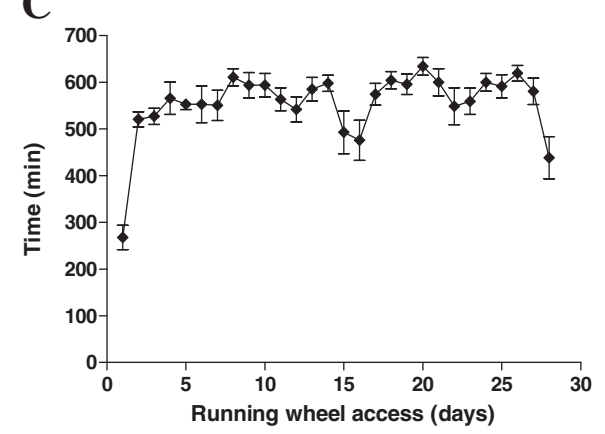

D

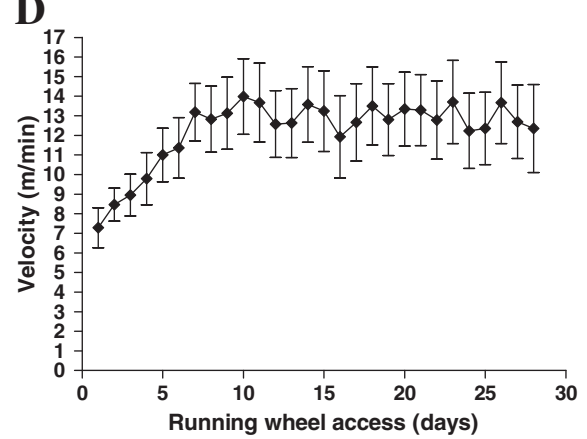

Figure 1 (A) Experimental timeline (see methods for details; $D=$ day) and (B) average distance run, (C) average amount of time spent running and (D) average velocity of running per $24 \mathrm{~h}$ over 4 weeks of running wheel access. Data represent means \pm S.E.M.

\section{Immunostaining}

For epifluorescent detection of Ki67, BrdU and Calbindin, a protocol similar to that implemented in previous studies was employed [22,23]. For Ki67 staining, a primary polyclonal anti-Ki67 antibody (rabbit anti-Ki67-antibody; 1:250; NCL-Ki67p, Novacastra, Newcastle upon Tyne, UK) was used with a secondary goat anti-rabbit IgG (Cy3 labelled; 1:250, Jackson Immunoresearch Laboratories Inc. West Grove, PA, USA). Sections were counterstained with the fluorescent DNA marker 4;6-diamidino-2'-phenylindoledihydrochloride (DAPI in TBS; 1:10,000; Sigma, Germany). For BrdU and calbindin staining, free-floating sections were stained with anti-BrdU (1:400, rat anti-BrdU, AbD Serotec, Raleigh, NC) and anti-Calbindin (1:2000; rabbit monoclonal anti-Calbindin D-28 k, SWANT, Bellinzona, Switzerland) antibodies. Secondary antibodies used were donkey anti-rat IgG (Cy3 labelled, 1:400; Jackson Immunoresearch Inc.) and donkey anti-rabbit IgG (Cy2 labelled; 1:300; Jackson Immunoresearch Inc.). For the immunoperoxidase detection of doublecortin, a procotol similar to that employed by
Rao and Shetty [24] was used. A primary goat polyclonal anti-DCX antibody (Doublecortin; 1:200, sc-8066, Santa Cruz Biotechnology, Santa Cruz, CA) was used with a biotinylated rabbit anti-goat IgG (1:300; Jackson Immunoresearch Laboratories Inc.) and 3,3'-diaminobenzidine (DAB) as the chromogen.

\section{Quantification of BrdU- and Ki67-positive cells}

To quantify the number of BrdU- and Ki67-positive cells across the rostro-caudal extent of the dentate gyrus, a modified stereological approach was employed similar to that described [25].

\section{Immunofluorescence analysis}

Fluorescent signals were imaged in z-stacks at $1 \mu \mathrm{m}$ intervals using Zeiss Axiovert confocal laser scanning microscope 510 with a $40 x$ objective. Fifty BrdU-positive cells within the subgranular zone and the granule cell layer were analysed for co-expression of BrdU and the neuronal maturation marker calbindin and percentages 
were determined. This was to determine the proportion of BrdU + cells that differentiated into neurons.

\section{Quantification of DCX-positive neurons}

Estimation of the total number of DCX-positive neurons was determined using unbiased stereology with the optical fractionator method and the semiautomatic StereoInvestigator system (MicroBrightField Inc., Williston, VT, USA). For this purpose, the granule cell layer of the hippocampal dentate gyrus was traced in every $6^{\text {th }}$ section and the reference volume was determined. Immunopositive cells were quantified by systematic random sampling using a scan grid size of $200 \times 200 \mu \mathrm{m}$ and a counting frame of $100 \times 100 \mu \mathrm{m}$. Cells that intersected the uppermost focal plane or the lateral exclusion borders of the counting frame were not quantified.

\section{Statistical analysis}

Numerical analyses were performed using SPSS software (SPSS Inc, Chicago, USA) and GraphPad Prism software. One- and two-way analysis of variance (ANOVA) were used, followed by one-tailed post-hoc tests (Tukey's and Bonferroni's). The Pearson's correlation coefficient was used to establish correlations between running distances, behaviour and cell counts. Differences were deemed statistically significant at $\mathrm{p}<0.05$.

\section{Results}

\section{Running behaviour}

Mice began running an average of $2.10 \mathrm{~km} /$ night on day 1 and steadily increased activity each day towards an average peak of $8.37 \mathrm{~km} /$ night on day 10 , generally reaching a plateau from this point (Figure 1B). Over the 28 day running period, the cumulative distances run were on average between 65.50 and $342.47 \mathrm{~km}$. Mice were spending up to 619.29 minutes running per night with speeds of up to $13.50 \mathrm{~m} / \mathrm{min}$ (Figure 1C and 1D).

\section{Open field behaviour}

The open field is a test of locomotor activity, exploration and anxiety-related behaviour. A two-way ANOVA revealed a significant main effect of treatment $\left(\mathrm{F}_{(1,55)}=9.01\right.$, $\mathrm{p}<0.01)$ without a main effect of time $\left(\mathrm{F}_{(1,55)}=1.32\right.$, n.s. $)$ or a significant treatment $\mathrm{x}$ time interaction effect $\left(\mathrm{F}_{(1,55)}=0.77\right.$, n.s.) on locomotor activity (indexed by total distance travelled; Figure 2A). Post-hoc analysis revealed that 28-day running wheel mice displayed a statistically significant $(\mathrm{p}<0.05)$ difference in locomotor activity across the 20-minute open field test compared to controls.

Concerning exploratory activity (rearing; Figure 2B) in the open field, a two-way ANOVA again revealed a significant main effect of treatment $\left(\mathrm{F}_{(1,55)}=23.67, \mathrm{p}<0.001\right)$ in the absence of either a main effect of time $\left(F_{(1,55)}=0.01\right.$, n.s.) or an interaction $\left(\mathrm{F}_{(1,55)}=0.79\right.$, n.s.). Both 14- and 28-
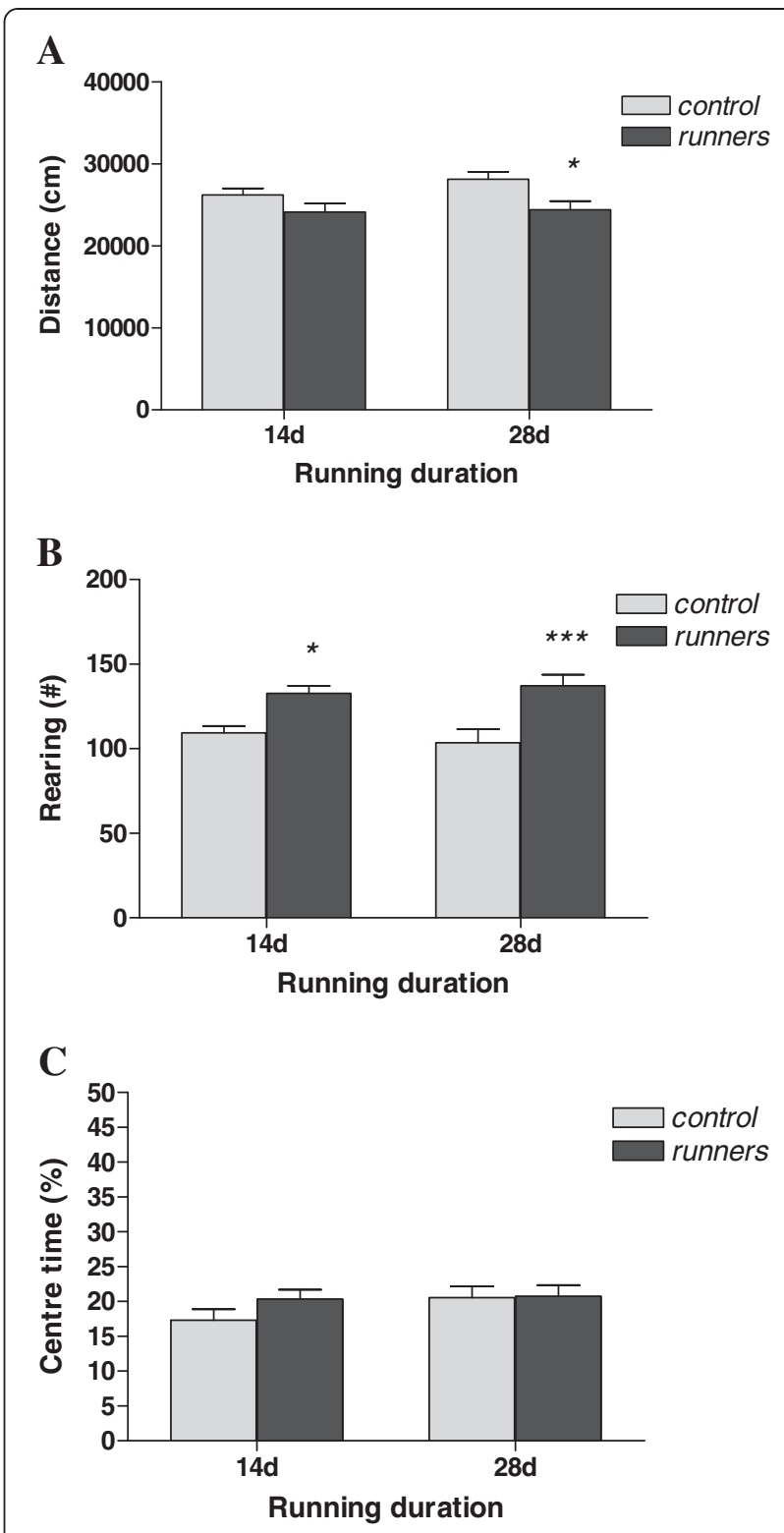

Figure 2 Behaviour of running (14-day and 28-day) and control mice during a 20-min open field test. $\ln (\mathbf{A}),(\mathbf{B})$ and (C),

locomotor activity (distance moved), exploration (rearing) and anxiety-related behaviour (\% centre time) are represented respectively. ${ }^{*} p<0.05,{ }^{* *} p<0.001$ vs. corresponding control. $N=14-16$ per group. Data represent means \pm S.E.M.

day running mice exhibited significantly increased rearing activity as assessed using post-hoc Bonferroni's test (14-day runners: $\mathrm{p}<0.05$; 28-day runners: $\mathrm{p}<0.001$ ). This difference was significant across all 5-minute subdivisions of the 20-minute test (data not shown).

No significant main effects of treatment $\left(\mathrm{F}_{(1,55)}=1.11\right.$, n.s. $)$, time $\left(\mathrm{F}_{(1,55)}=1.42\right.$, n.s. $)$ or an interaction $\left(\mathrm{F}_{(1,55)}=0.85\right.$, n.s.) were found on total \% time spent in the centre (index of anxiety-related behaviour; Figure 2C) of the open field using a two-way ANOVA. 


\section{Effect of wheel running on behaviour in the light/dark box}

In the light/dark box, a test of anxiety that exploits a rodent's aversion to a brightly lit space, there were no significant effects of exercise on any of the anxietyrelated parameters measured (Figure 3). This includes the main indices such as latency to enter light box $\left(\mathrm{F}_{(2,27)}=0.55\right.$, n.s. $)$; light box entries $\left(\mathrm{F}_{(2,27)}=2.08\right.$, n.s. $)$ and percentage time spent in light box $\left(\mathrm{F}_{(2,27)}=1.42\right.$, n.s. $)$.

\section{Effect of wheel running on proliferation of granule cell precursors}

To determine the effects of the different running durations on the proliferation period of the neurogenic process, we quantified the numbers of Ki67+ cells in the subgranular zone/granule cell layer of the dentate gyrus, a protein present in proliferating cells [23] (Figure 4A and B). A two-way ANOVA revealed significant main effects of treatment $\left(\mathrm{F}_{(1,27)}=15.80, \mathrm{p}<0.001\right)$ and time $\left(\mathrm{F}_{(1,27)}=15.00\right.$, $\mathrm{p}<0.001)$ without an interaction $\left(\mathrm{F}_{(1,27)}=1.57\right.$, n.s.). Posthoc Bonferroni's test found that the 14-day runners had a significantly increased number of Ki67-positive cells in the dentate gyrus compared to controls $(\mathrm{p}<0.01)$. While 28day runners still showed an increased number of proliferating cells compared to controls, this difference did not attain statistical significance.

Effect of 2 and 4 weeks wheel running on the fate and rate of maturation of new neurons in the dentate gyrus To assess the effects of the two wheel running durations on the fate of cells that proliferated after the initiation of running we labelled cells with BrdU for three days subsequent to commencement of running (Figure 4C and D). A two-way ANOVA found both a significant main effect of treatment $\left(\mathrm{F}_{(1,38)}=15.80\right.$, $\mathrm{p}<0.001)$ and time $\left(\mathrm{F}_{(1,38)}=17.11, \mathrm{p}<0.001\right)$ without an interaction effect $\left(\mathrm{F}_{(1,38)}=0.05\right.$, n.s. $)$. An increased number of BrdU-positive cells in the dentate gyrus was seen after both 14 and 28 days of running in these mice as shown by post-hoc analysis $(\mathrm{p}<0.05)$. This gives runners on average a $70.71 \%$ increase in BrdU-positive cells at the 28 day time-point. To assess the rate of maturation of new neurons in the dentate gyrus of running mice, the number of BrdUpositive cells that co-expressed the mature neuronal marker calbindin were quantified and compared between groups (Figure 4E and F). As expected (as it takes longer than 14 days for new neurons to become calbindin-positive) no significant difference was observed in the number of 14 day BrdU-positive neurons that were calbindin-positive. A $t$-test revealed a significant increase in the percentage of BrdU/calbindin positive cells in the dentate gyrus of 28-day running mice compared to controls $\left(\mathrm{t}_{(17)}=2.18, \mathrm{p}<0.05\right.$; controls: $63.88 \pm 3.40 \%$; runners: $72.66 \pm 2.30 \%)$.

\section{Effect of running on the number of DCX-positive neurons} in the dentate gyrus

To assess the effect of wheel running on the differentiation of newly born cells, we estimated the total number of DCX-positive neurons in the hippocampal dentate gyrus. A two-way ANOVA revealed both a significant main effect of time $\left(\mathrm{F}_{(1,35)}=7.32, \mathrm{p}=0.01\right)$ and exercise $\left(F_{(1,35)}=33.86, p<0.0001\right)$. A Bonferroni's test showed that both 14 and $28 \mathrm{~d}$ runners had higher DCX-positive cells in the dentate gyrus compared to controls (Figure 4G and $4 \mathrm{H}$ ). The number of DCX-positive cells was also quantified in the dentate gyrus of the separate cohort of animals exposed to the light/dark box. A one-way ANOVA revealed a significant difference between the groups $(F(2,9)=13.27, p=0.002)$. A post-hoc Tukey's test showed that the running wheel mice had higher DCX numbers compared to both the sedentary $(\mathrm{p}<0.05)$ and blocked wheel $(\mathrm{p}<0.01)$ control groups with the difference more pronounced in the latter (Figure 3D).

\section{Correlation analysis of running, open field behaviour and neurogenesis markers in exercising mice}

Regression analysis between the measures of open field behaviour and neurogenesis in running mice revealed noteworthy correlations. In both the 14- and 28-day runners, there was a significant positive correlation between distance run on the running wheels and distance travelled in the open field (14d: $r_{p}=0.54, p<0.05,28 d: r_{p}=0.80, p=0.01$; Table 1). Concerning anxiety-related behaviour, in the 28 day runners there was a significant negative correlation between the numbers of Ki67+ cells in the dentate gyrus and the total \% time spent in the centre of the open field (Table 1: \% time centre total: $\mathrm{r}_{\mathrm{p}}=-0.89, \mathrm{p}=0.01$ ).

\section{Discussion}

Both 14- and 28-days of voluntary running in mice affected different aspects of open field behaviour, but neither exercise dose produced anxiolytic or anxiogenic effects. Moreover, the 28 day exercise dose did not produce changes in anxiety-related behaviour in the light/ dark box test. Both durations influenced the various stages of neurogenesis with proliferation increased after 14 days, survival elevated after both 14 and 28 days and the rate of differentiation and maturation of newly born neurons increased in the 28-day runners compared to controls. Regression analysis identified a significant correlation between the proliferation marker and the anxiety-related parameter of total time spent in the centre of the open field but not with markers of survival, differentiation and maturation of adult born new neurons. 


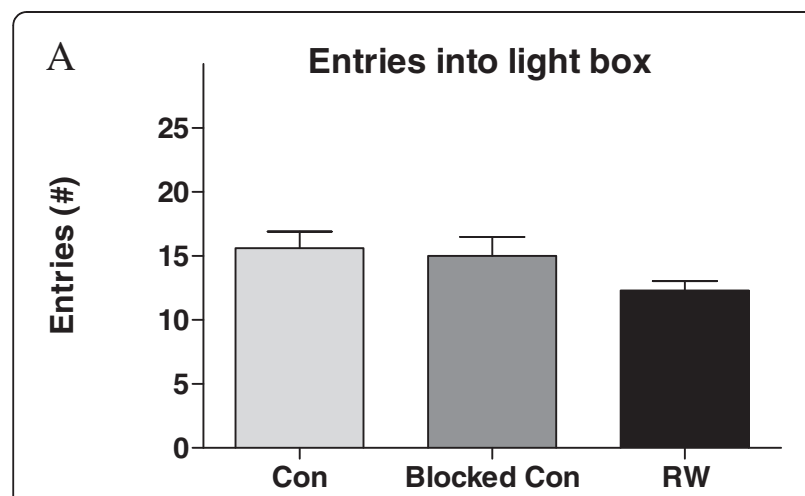

B 5 Time spent in light box
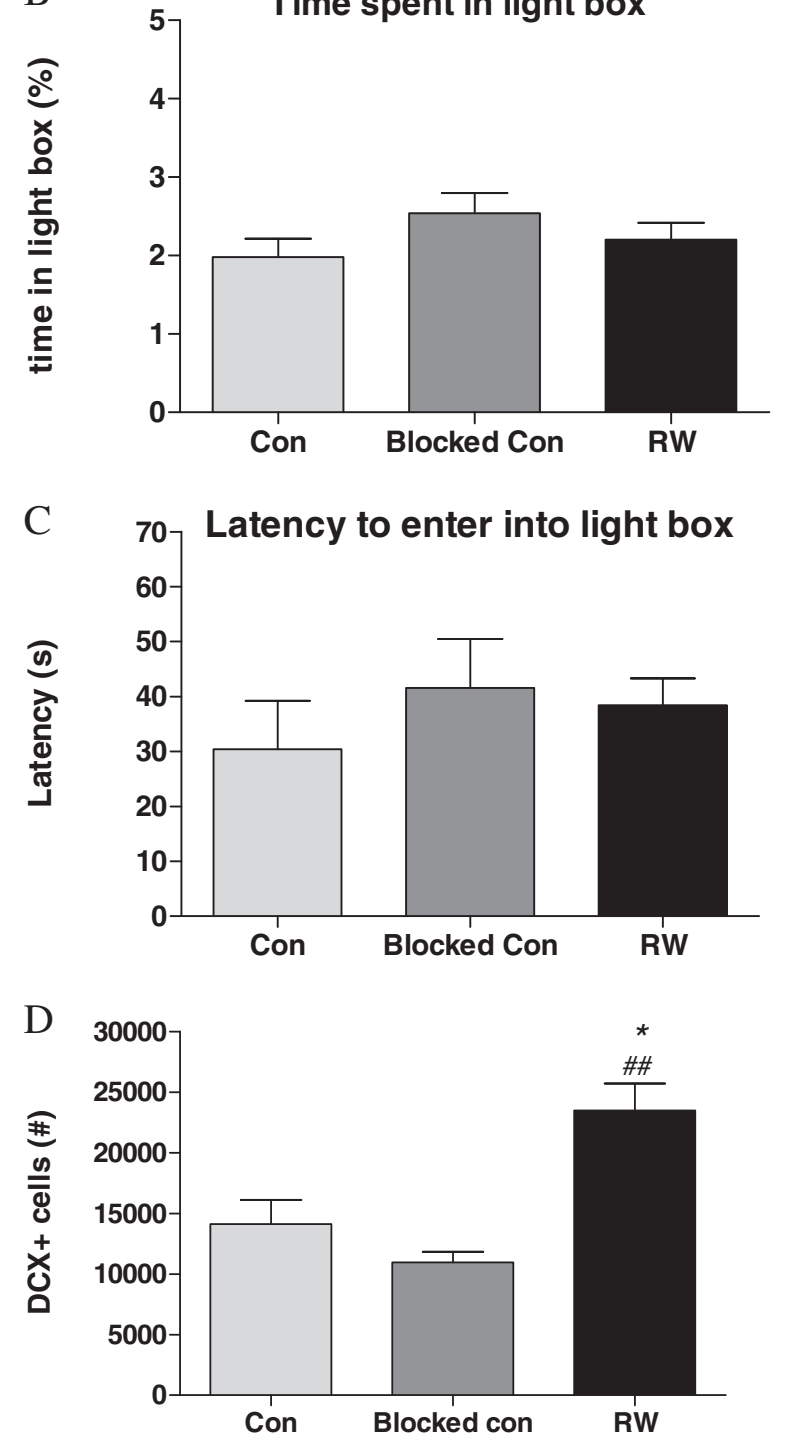

Figure 3 (A) 14 days running caused significantly increased proliferating cell number (indexed by Ki67 immunoreactivity) in the dentate gyrus of male $\mathrm{C} 57 \mathrm{BI} / 6 \mathrm{~J}$ mice, no longer present after 28 days. (B) Marker for proliferation: fluorescent immunohistochemistry against Ki67 (red). (C) Both 14-days and 28days of running increased survival (indexed by BrdU staining) in the dentate gyrus in these animals. (D) Representative photomicrograph showing a marker for survival: BrdU-immunoreactive cells in the dentate gyrus (red). (E) and (F) Running increases the number of new born neurons that reach maturation: 28-days running significantly increased the $\%$ of BrdU-labelled cells (red) that colocalised with calbindin (mature neuronal marker: green). (G) and (H) Both 14-days and 28-days running increased differentiation (indexed by DCX staining) of newly born cells into immature neurons in the dentate gyrus. $(B+D)$ Scale bar $=50 \mu \mathrm{m}$ (F) Scale bar $=20 \mu \mathrm{m}(\mathrm{H})$ Scale bar $=70 \mu \mathrm{m}$ Data represent means \pm S.E.M. ${ }^{*} p<0.05$, ${ }^{* *} p<0.01,{ }^{* *} p<0.001$ vs. corresponding control.

\section{Exercise and neurogenesis}

Neural plasticity in the form of hippocampal neurogenesis is known to be potently increased subsequent to exercise in a cell population connected to hippocampalrelated behaviours [26]. In terms of exercise-induced proliferation $[1,16,27]$, enhanced survival of the young granule cells $[3,16,28,29]$ and the increased rate of differentiation and maturation into neurons [3,30,31], our results are consistent with these foregoing studies.

\section{Exercise and behaviour}

In the open field, the 28-day running mice moved significantly less than controls, suggesting decreased locomotor activity. A similar pattern was observed in the 14-day runners. Furthermore, both 14- and 28-day runners reared significantly more during the 20 -minute test. One interpretation is that the running mice exhibited decreased reactivity to the aversiveness of the open field environment and increased exploration. A similar behavioural pattern has been observed in other tests in previous studies [32,33].

Concerning the classic open field index of anxiety; the amount of time spent in the centre of the arena, neither running period was anxiolytic or anxiogenic in either the 14- or 28-day runners. Although both running durations were previously shown to produce anti-anxiety effects in the open field $[19,20]$, there are also other studies reporting increased anxiety or no change [17,31,34]. Furthermore, Fuss and co-workers (2010) demonstrated a similar decrease in locomotor activity in the open field without clear changes in anxiety-related behaviour; they report an effect of running on "distance to walls" during the second half of the 10 minute test (arguably an activity- rather than an anxiety-related measure) and do not describe other centre zone alterations. The open field was also the first of a list of tests they performed on their exercising mice; the increased anxiety was apparent in subsequent tests e.g. the light/dark box. 


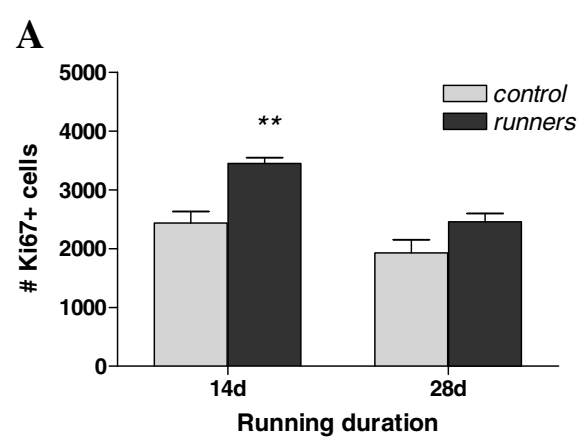

C

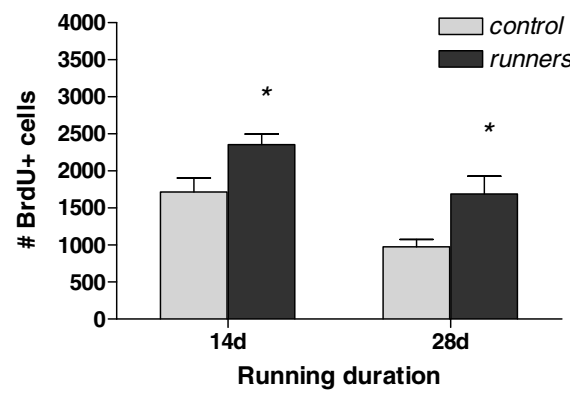

$\mathbf{E}$

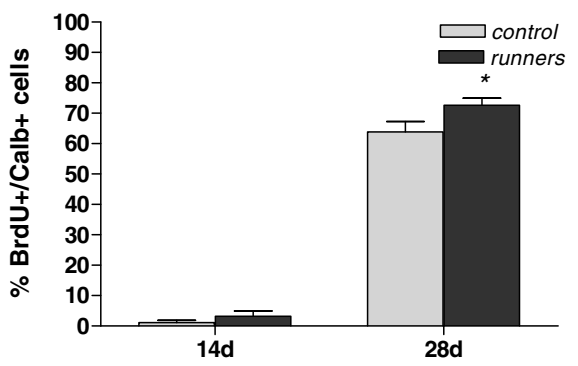

G

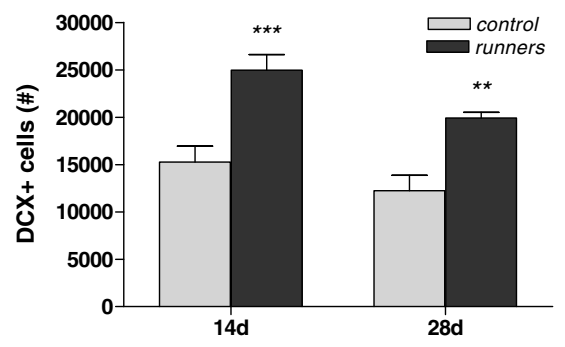

B

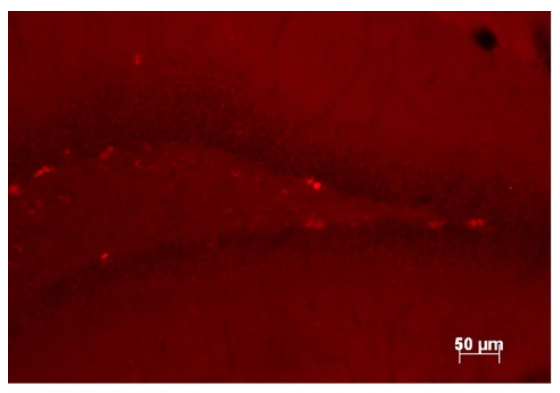

D

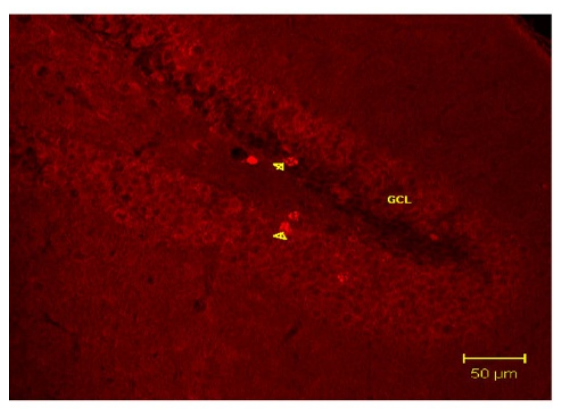

F

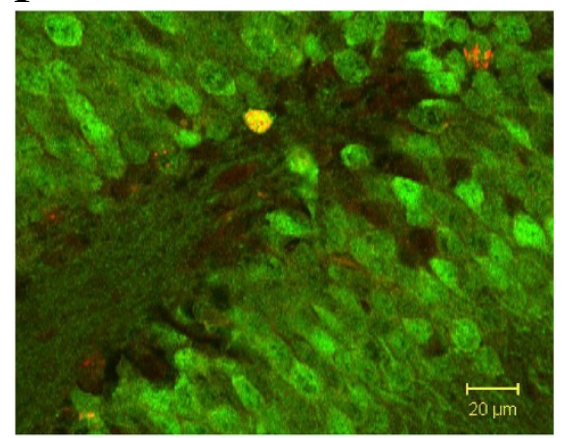

H

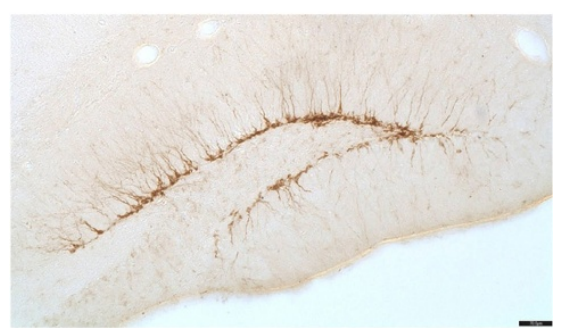

Figure 4 Behaviour of running (28-day; RW) and control (Sedentary (con) and Blocked Wheel (blocked con)) mice during a 5-min light/ dark box test. In (A), (B) and (C), entries into light box, \% time spent in light box and latency to enter light box are represented respectively. $N=10$ per group. In (D) the total number of DCX positive cells in the dentate gyrus from the second cohort of animals in which the light/dark box was tested are shown. ${ }^{*} p<0.05$ vs. con, \#\#p $<0.01$ vs. blocked con. Data represent means \pm S.E.M. 
Table 1 Correlations between running, open field behaviour and neurogenesis in exercising male C57BI/6 J mice

\begin{tabular}{|c|c|c|c|c|}
\hline 14d Runner & $\frac{\text { Distance }}{\text { Total }}$ & $\frac{\text { Rearing }}{\text { Total }}$ & $\frac{\text { \%Time Centre }}{\text { Total }}$ & Running Distance \\
\hline Running Distance & & ns & ns & \\
\hline$P$ value & 0.02 & & & - \\
\hline$r$ & 0.54 & & & \\
\hline Ki67 & ns & ns & ns & ns \\
\hline \multicolumn{5}{|l|}{$P$ value } \\
\hline \multicolumn{5}{|l|}{$r$} \\
\hline BrdU & ns & ns & ns & ns \\
\hline \multicolumn{5}{|l|}{$P$ value } \\
\hline \multicolumn{5}{|l|}{$r$} \\
\hline \# DCX & ns & ns & ns & ns \\
\hline \multicolumn{5}{|l|}{$P$ value } \\
\hline \multicolumn{5}{|l|}{$r$} \\
\hline \multirow[t]{2}{*}{ 28d Runner } & Distance & Rearing & \%Time Centre & Running Distance \\
\hline & Total & Total & Total & \\
\hline Running Distance & & ns & ns & - \\
\hline$P$ value & 0.01 & & & \\
\hline$r$ & 0.80 & & & \\
\hline \# Ki67 & ns & & & ns \\
\hline$P$ value & & 0.09 & 0.01 & \\
\hline$r$ & & 0.73 & -0.89 & \\
\hline \# BrdU & ns & ns & ns & ns \\
\hline \multicolumn{5}{|l|}{$P$ value } \\
\hline \multicolumn{5}{|l|}{$r$} \\
\hline$\%$ BrdU/Calbindin & ns & ns & ns & ns \\
\hline \multicolumn{5}{|l|}{$P$ value } \\
\hline \multicolumn{5}{|l|}{$r$} \\
\hline \# DCX & ns & ns & ns & ns \\
\hline \multicolumn{5}{|l|}{$P$ value } \\
\hline$r$ & & & & \\
\hline
\end{tabular}

$r=$ correlation coefficient.

To assess whether no change in anxiety-related behaviour was due to a possible lack of sensitivity of the open field as a measure, we also performed the light/dark box test on a separate cohort of exercising mice. The outcome was consistent with the findings from the open field, i.e. no significant change in anxiety-related indices. Together, these results suggest that under these experimental conditions chronic voluntary wheel running is not anxiolytic or anxiogenic. Furthermore, there was no alteration between the control group without running wheel and the blocked wheel controls, indicating that the presence or absence of a (blocked) wheel did not matter for the anxiety-related behaviour of the control group.

\section{Correlation between exercise-induced hippocampal proliferation and anxiety}

We found a significant negative correlation between anxiety in the open field (centre time) and the number of cells positive for Ki67, which labels proliferating cells that are still pluripotent and is thus not strictly a neuronal marker, in the dentate gyrus after 28 days running. This implies that the more proliferation of hippocampal precursor cells (that includes both neuronal and glial precursors), the more anxious the animal at this time-point (see Table 1). Importantly, we did not however observe a correlation between open field anxiety and either the survival (BrdU positive cell number) or maturation (\% BrdU/Calbindin maturation rate) phases of neurogenesis. 
Thus, there was no apparent relationship between open field anxiety and mature newly formed neurons integrated into the existing hippocampal circuitry, which are capable of recruitment for behavioural functioning [35]. Fuss and co-workers (2010) observed a significant negative correlation between anxiety and neurogenesis after 6 weeks running; nevertheless, this was with doublecortin, a marker of newly born cells that have already differentiated into neurons. Furthermore, doublecortin levels were correlated to anxiety-measures assessed 19 to 23 days prior to the sacrifice of the animals, i.e. in contrast to our experiment, there was a time gap between the behavioural test and the assessment of neurogenic markers. Taken together, the fact that we did not see the correlation between anxiety and the rate of maturation of newly born neurons and no change in anxiety-related behaviour in the open field the day before sacrifice suggests that functionally mature neurons present at the time point of testing are not, in isolation, required for the genesis of anxiety per se as previously asserted by Fuss and co-workers (2010). An alternative explanation is that learning due to the repeated experience and/or prolonged time involved in the repeated behavioural testing in their study involved recruitment of the newly produced neurons and thereby underlies the correlation between maturation and anxiety-related behaviour.

Our result seems to conflict with a more recent study from the group of Fuss et al. [36]. They showed that irradiation blocked the anxiogenic effect of exercise, suggesting a role for neurogenesis in producing this behaviour. There are some possible explanations for the apparent conceptual discrepancy between the studies. For instance, a similar anxiety behavioural battery was used as in their previous study, testing open field first, followed by the O-maze and the light/dark box. Thus, the effect of repeated testing and the role played by neurogenesis under these circumstances cannot be excluded, as detailed above. Furthermore, while there appears to be an effect on anxiety in the first test, the open field (decreased centre time), this could be arguably secondary to the decreased locomotor activity in these mice. In addition, the use of irradiation to inhibit neurogenesis is not ideal due to possible side effects and this manipulation even appears to increase anxiety in the light/dark box. In sum, the findings of this particular study, while conflicting, are not conclusive

\section{Conclusions}

Overall, our data show that while voluntary wheel running increases neurogenesis measures in mice, it does not produce an anxiolytic or anxiogenic effect in the open field. Most studies to date examining the relationship between neurogenesis and anxiety have been lossof-function approaches $[6,12,13]$. The lack of an effect of exercise on anxiety in our mice, combined with the robust concomitant increase in neurogenesis implies that, as distinct from the findings of Fuss et al [17], a pure gain-of-neurogenesis in normal mice does not necessarily alter anxiety-related behaviour without further stimulation. Taken together, this suggests that neurogenesis may be involved in the learning of anxiety, but does not produce anxiety per se.

\section{Abbreviations}

BDNF: Brain-derived neurotrophic factor; BrdU: 5'-bromo-2'-deoxyuridine.

\section{Competing interests}

The authors declare that they do not have any competing interests.

\section{Authors' contributions}

LG carried out the behavioural and immunohistochemical studies, performed the statistical analyses and drafted the manuscript. DCL participated in the conception and design of the study and in drafting the manuscript. MHdA was involved in the critical revision of the manuscript for the final draft. WW participated in the conception of the study and in the critical revision of the manuscript. SH conceived the study, participated in its design, coordination and interpretation and analysis of the results and helped to draft the manuscript. All authors read and approved the final manuscript.

\section{Acknowledgements}

This work was partially supported by the Bundesministerium für Bildung und Forschung within the framework of NGFN-Plus (FKZ: 01GS0850), the European Commission (EUMODIC: LSHG-2006-037188), the "Helmholtz Alliance for Mental Health in an Ageing Society" (HELMA), GLIA/Neurogenese from DLR/BMBF (01GN1009C) and the Bayerischer Forschungsverbund Stammzellen (F2-G2410-10c/20097).

\section{Author details}

'Institute of Developmental Genetics, Helmholtz Zentrum München, German Research Center for Environmental Health, Neuherberg/Munich, Germany. ${ }^{2}$ Institute of Experimental Genetics, Helmholtz Zentrum München, German Research Center for Environmental Health, Neuherberg/Munich, Germany. ${ }^{3}$ German Mouse Clinic, Helmholtz Zentrum München, German Research Center for Environmental Health, Neuherberg/Munich, Germany. ${ }^{4}$ Technische Universität München, Lehrstuhl für Entwicklungsgenetik,

Freising-Weihenstephan, Germany. ${ }^{5}$ Technische Universität München, Lehrstuhl für Experimentelle Genetik, Freising-Weihenstephan, Germany. ${ }^{6}$ Deutsches Zentrum für Neurodegenerative Erkrankungen e. V. (DZNE), Site Munich, Germany. ${ }^{7}$ Max Planck Institute of Psychiatry, Munich, Germany.

Received: 28 October 2011 Accepted: 8 June 2012

Published: 8 June 2012

\section{References}

1. Kronenberg G, Bick-Sander A, Bunk E, Wolf C, Ehninger D, Kempermann G: Physical exercise prevents age-related decline in precursor cell activity in the mouse dentate gyrus. Neurobiol Aging 2006, 27(10):1505-1513.

2. Leasure $J$, Jones $M$ : Forced and voluntary exercise differentially affect brain and behavior. Neuroscience 2008, 156(3):456-465.

3. van Praag H, Kempermann G, Gage FH: Running increases cell proliferation and neurogenesis in the adult mouse dentate gyrus. Nat Neurosci 1999, 2(3):266-270.

4. Kempermann G, Jessberger S, Steiner B, Kronenberg G: Milestones of neuronal development in the adult hippocampus. Trends Neurosci 2004, 27(8):447-452.

5. Kempermann G: The neurogenic reserve hypothesis: what is adult hippocampal neurogenesis good for? Trends Neurosci 2008, 31(4):163-169.

6. Saxe MD, Battaglia F, Wang JW, Malleret G, David DJ, Monckton JE, Garcia $A D$, Sofroniew MV, Kandel ER, Santarelli L, et al: Ablation of hippocampal neurogenesis impairs contextual fear conditioning and synaptic plasticity in the dentate gyrus. Proc Natl Acad Sci U S A 2006, 103(46):17501-17506. 
7. Zhang $C L$, Zou Y, He W, Gage FH, Evans RM: A role for adult TLX-positive neural stem cells in learning and behaviour. Nature 2008, 451(7181): 1004-1007.

8. Sahay A, Scobie KN, Hill AS, O'Carroll CM, Kheirbek MA, Burghardt NS, Fenton AA, Dranovsky A, Hen R: Increasing adult hippocampal neurogenesis is sufficient to improve pattern separation. Nature 2011 472(7344):466-470.

9. David DJ, Samuels BA, Rainer Q, Wang JW, Marsteller D, Mendez I, Drew M, Craig DA, Guiard BP, Guilloux JP, et al: Neurogenesis-dependent and independent effects of fluoxetine in an animal model of anxiety/ depression. Neuron 2009, 62(4):479-493.

10. Hayashi F, Takashima N, Murayama A, Inokuchi K: Decreased postnatal neurogenesis in the hippocampus combined with stress experience during adolescence is accompanied by an enhanced incidence of behavioral pathologies in adult mice. Mol Brain 2008, 1:22.

11. Santarelli L, Saxe M, Gross C, Surget A, Battaglia F, Dulawa S, Weisstaub N, Lee J, Duman R, Arancio O, et al: Requirement of hippocampal neurogenesis for the behavioral effects of antidepressants. Science 2003 301(5634):805-809.

12. Revest JM, Dupret D, Koehl M, Funk-Reiter C, Grosjean N, Piazza PV, Abrous DN: Adult hippocampal neurogenesis is involved in anxiety-related behaviors. Mol Psychiatry 2009, 14(10):959-967.

13. Bergami M, Rimondini R, Santi S, Blum R, Gotz M, Canossa M: Deletion of TrkB in adult progenitors alters newborn neuron integration into hippocampal circuits and increases anxiety-like behavior. Proc Natl Acad Sci U S A 2008, 105(40):15570-15575.

14. Schloesser RJ, Manji HK, Martinowich K: Suppression of adult neurogenesis leads to an increased hypothalamo-pituitary-adrenal axis response. Neuroreport 2009, 20(6):553-557.

15. Onksen $J$, Brown EJ, Blendy JA: Selective deletion of a cell cycle checkpoint kinase (ATR) reduces neurogenesis and alters responses in rodent models of behavioral affect. Neuropsychopharmacology: official publication of the American College of Neuropsychopharmacology 2011, 36(5):960-969.

16. Snyder JS, Glover LR, Sanzone KM, Kamhi JF, Cameron HA: The effects of exercise and stress on the survival and maturation of adult-generated granule cells. Hippocampus 2009, 19(10):898-906.

17. Fuss J, Ben Abdallah NM, Vogt MA, Touma C, Pacifici PG, Palme R, Witzemann V, Hellweg R, Gass P: Voluntary exercise induces anxiety-like behavior in adult C57BL/6J mice correlating with hippocampal neurogenesis. Hippocampus 2010, 20(3):364-376.

18. Voikar V, Rossi J, Rauvala H, Airaksinen MS: Impaired behavioural flexibility and memory in mice lacking GDNF family receptor alpha2. The European journal of neuroscience 2004, 20(1):308-312.

19. Duman $\mathrm{CH}$, Schlesinger L, Russell DS, Duman RS: Voluntary exercise produces antidepressant and anxiolytic behavioral effects in mice. Brain Res 2008, 1199:148-158.

20. Salam JN, Fox JH, Detroy EM, Guignon MH, Wohl DF, Falls WA: Voluntary exercise in C57 mice is anxiolytic across several measures of anxiety. Behav Brain Res 2009, 197(1):31-40.

21. Snyder JS, Radik R, Wojtowicz JM, Cameron HA: Anatomical gradients of adult neurogenesis and activity: young neurons in the ventral dentate gyrus are activated by water maze training. Hippocampus 2009, 19(4):360-370.

22. Zhang WJ, Tan YF, Yue JT, Vranic M, Wojtowicz JM: Impairment of hippocampal neurogenesis in streptozotocin-treated diabetic rats. Acta Neurol Scand 2008, 117(3):205-210.

23. Wojtowicz JM, Kee N: BrdU assay for neurogenesis in rodents. Nat Protoc 2006, 1(3):1399-1405.

24. Rao MS, Shetty AK: Efficacy of doublecortin as a marker to analyse the absolute number and dendritic growth of newly generated neurons in the adult dentate gyrus. The European journal of neuroscience 2004, 19 (2):234-246.

25. Beauquis J, Roig P, Homo-Delarche F, De Nicola A, Saravia F: Reduced hippocampal neurogenesis and number of hilar neurones in streptozotocin-induced diabetic mice: reversion by antidepressant treatment. Eur J Neurosci 2006, 23(6):1539-1546.

26. Bannerman DM, Rawlins JN, McHugh SB, Deacon RM, Yee BK, Bast T, Zhang WN, Pothuizen $\mathrm{HH}$, Feldon J: Regional dissociations within the hippocampus-memory and anxiety. Neurosci Biobehav Rev 2004, 28(3):273-283.

27. Clark PJ, Kohman RA, Miller DS, Bhattacharya TK, Haferkamp EH, Rhodes JS: Adult hippocampal neurogenesis and c-Fos induction during escalation of voluntary wheel running in C57BL/6J mice. Behav Brain Res 2010, 213(2):246-252.

28. Holmes MM, Galea LA, Mistlberger RE, Kempermann G: Adult hippocampal neurogenesis and voluntary running activity: circadian and dosedependent effects. J Neurosci Res 2004, 76(2):216-222.

29. van Praag H, Christie BR, Sejnowski TJ, Gage FH: Running enhances neurogenesis, learning, and long-term potentiation in mice. Proc Natl Acad Sci U S A 1999, 96(23):13427-13431.

30. Allen DM, van Praag H, Ray J, Weaver Z, Winrow CJ, Carter TA, Braquet R, Harrington $\mathrm{E}$, Ried $\mathrm{T}$, Brown KD, et al: Ataxia telangiectasia mutated is essential during adult neurogenesis. Genes Dev 2001, 15(5):554-566.

31. Marlatt MW, Lucassen PJ, van Praag H: Comparison of neurogenic effects of fluoxetine, duloxetine and running in mice. Brain Res 2010, 1341:93-99.

32. Binder E, Droste SK, Ohl F, Reul JM: Regular voluntary exercise reduces anxiety-related behaviour and impulsiveness in mice. Behav Brain Res 2004, 155(2):197-206.

33. Garcia-Capdevila S, Portell-Cortes I, Torras-Garcia M, Coll-Andreu M, CostaMiserachs D: Effects of long-term voluntary exercise on learning and memory processes: dependency of the task and level of exercise. Behav Brain Res 2009, 202(2):162-170.

34. Pietropaolo S, Feldon J, Alleva E, Cirulli F, Yee BK: The role of voluntary exercise in enriched rearing: a behavioral analysis. Behav Neurosci 2006, 120(4):787-803.

35. Zhao C, Deng W, Gage FH: Mechanisms and functional implications of adult neurogenesis. Cell 2008, 132(4):645-660.

36. Fuss J, Ben Abdallah NM, Hensley FW, Weber KJ, Hellweg R, Gass P: Deletion of running-induced hippocampal neurogenesis by irradiation prevents development of an anxious phenotype in mice. PLoS One 2010, 5(9):pii:e12769.

doi:10.1186/1471-2202-13-61

Cite this article as: Garrett et al:: Voluntary wheel running in mice increases the rate of neurogenesis without affecting anxiety-related behaviour in single tests. BMC Neuroscience 2012 13:61.

\section{Submit your next manuscript to BioMed Central and take full advantage of:}

- Convenient online submission

- Thorough peer review

- No space constraints or color figure charges

- Immediate publication on acceptance

- Inclusion in PubMed, CAS, Scopus and Google Scholar

- Research which is freely available for redistribution

Submit your manuscript at www.biomedcentral.com/submit
C BioMed Central 